\title{
Study of Magnetic and Structural Properties of Non-Stoichiometric NiZn Ferrites Prepared by Wet Method
}

\author{
A. Grusková, J. Sláma, M. Ušáková, M. ŠokA*, R. Dosoudil \\ AND J. DEGMOVÁ \\ Slovak University of Technology, Ilkovičova 3, 81219 Bratislava, Slovakia
}

\begin{abstract}
An iron-deficient $\left(\mathrm{Ni}_{0.33} \mathrm{Zn}_{0.67}\right)_{1+x} \mathrm{Fe}_{2-x} \mathrm{O}_{4}$ and stoichiometric $\mathrm{Ni}_{0.45} \mathrm{Zn}_{0.55} \mathrm{Fe}_{2} \mathrm{O}_{4}$ prepared by a wet method were studied using the Mössbauer spectroscopy and thermomagnetic measurements. For the iron-deficient sample the $T_{\mathrm{C}}$ is twice as large and the temperature coefficient of initial permeability is two orders of magnitude lower in comparison with the stoichiometric samples. The results are supplemented by the frequency dependence of the complex permeability.
\end{abstract}

PACS numbers: 75.50.Gg, 75.30.Cr, 75.30.-m, 82.80.Ej

\section{Introduction}

NiZn ferrites with a spinel structure have been extensively used in electronic devices because of their excellent magnetic properties at high frequency, high resistivity, mechanical hardness and chemical stability [1]. The properties of NiZn ferrites are strongly influenced by the composition and microstructure, which are sensitive to their preparation, for instance by wet chemical methods through aerosol route [1] or through hydrotalcite [2]. Zhiyuan et al. [3] showed that it is possible to obtain a good magnetically soft material by controlling the degree of iron deficiency. It is known that the maximum value of the magnetic permeability can be reached by zinc contents of around 0.7 ions per formula unit [4]. In this case however the Curie temperature is too low and this problem can be solved by increasing the iron deficiency in NiZn ferrite.

\section{Experimental}

The influence of the non-stoichiometry on magnetic properties of NiZn ferrite has been investigated for compositions given by the formula of $\left(\mathrm{Ni}_{0.33} \mathrm{Zn}_{0.67}\right)_{1+x} \mathrm{Fe}_{2-x} \mathrm{O}_{4}$, where values of $x$ were 0.0 and 0.20. The samples were denoted as $\mathrm{A}$ and $\mathrm{B}$. The stoichiometric composition $\mathrm{Ni}_{0.45} \mathrm{Zn}_{0.55} \mathrm{Fe}_{2} \mathrm{O}_{4}$ was prepared and was denoted as $\mathrm{C}$. The raw mixture of $\mathrm{Fe}\left(\mathrm{NO}_{3}\right)_{3} \cdot 9 \mathrm{H}_{2} \mathrm{O}, \quad \mathrm{Ni}\left(\mathrm{NO}_{3}\right)_{2} \cdot 6 \mathrm{H}_{2} \mathrm{O}$ and $\mathrm{Zn}\left(\mathrm{CH}_{3} \mathrm{COO}\right)_{2} \cdot 2 \mathrm{H}_{2} \mathrm{O}$ was dissolved in deionized water; glycine was added, the solution was then heated up to decomposition. Annealing at $850^{\circ} \mathrm{C}$ up to $1250{ }^{\circ} \mathrm{C}$ for $6 \mathrm{~h}$ was sufficient to reach an ordered spinel structure. The structural and phase constitution of resulting

\footnotetext{
* corresponding author; e-mail: martin.soka@stuba.sk
}

powders was analysed by the Mössbauer spectroscopy at room temperature by a constant acceleration spectrometer with the ${ }^{57} \mathrm{Co}(\mathrm{Rh})$ source. The temperature dependences of the magnetic susceptibility $\chi(T)$ was determined by the bridge method in an alternating magnetic field of $421 \mathrm{~A} / \mathrm{m}$ at $920 \mathrm{~Hz}$. The Curie temperature was evaluated from the $\chi(T)$ dependence. The complex permeability of synthesised samples was measured at room temperature in the frequency range $1 \mathrm{MHz}-1 \mathrm{GHz}$, using the impedance analyzer HP4191A.

\section{Results and discussion}

For sample B the Mössbauer spectrum consists of two individual subspectra resulting from a magnetic hyperfine field distribution with spectral area $A_{\text {rel }}=98.68 \%$ and average value of hyperfine magnetic field $B_{\mathrm{HF}}=$ $30.50 \mathrm{~T}$ and quadrupole splitting distribution corresponding to non-magnetic part of the sample with spectral area $A_{\text {rel }}=1.32 \%$ and average value of quadrupole splitting QS $=0.6266 \mathrm{~mm} / \mathrm{s}$. Sample $\mathrm{C}$ has magnetic

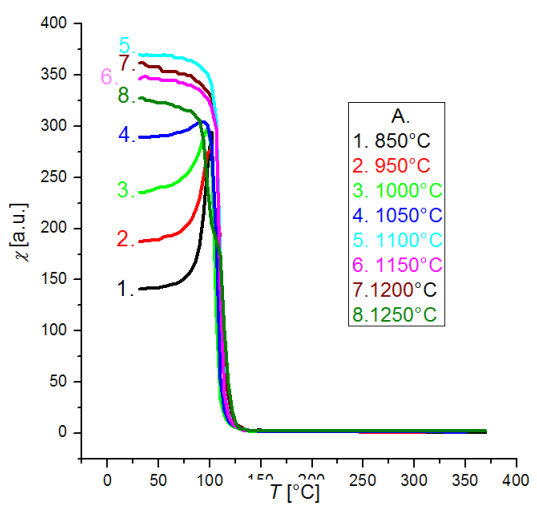

Fig. 1. Temperature dependences of initial susceptibility $\chi(T)$ of $\mathrm{Ni}_{0.33} \mathrm{Zn}_{0.67} \mathrm{Fe}_{2} \mathrm{O}_{4}$ (A) ferrite. 


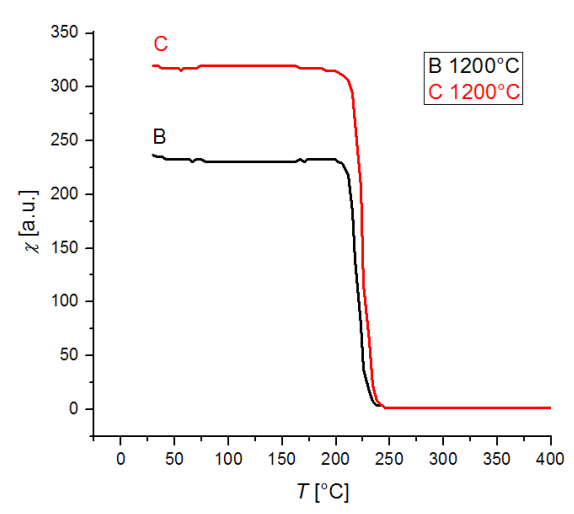

Fig. 2. Temperature dependences of $\chi(T)$ of $\mathrm{Ni}_{0.396} \mathrm{Zn}_{0.804} \mathrm{Fe}_{1.8} \mathrm{O}_{4}$ (B) and $\mathrm{Ni}_{0.45} \mathrm{Zn}_{0.55} \mathrm{Fe}_{2} \mathrm{O}_{4}$ (C) ferrites.

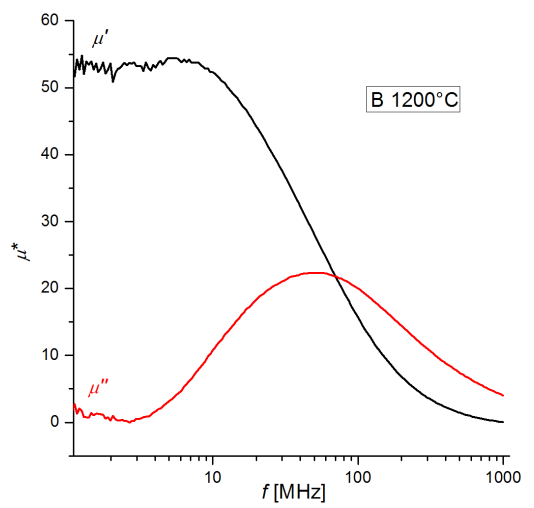

Fig. 3. Frequency dependence of real $\mu^{\prime}$ and imaginary $\mu^{\prime \prime}$ parts of complex permeability $\mu^{*}$ of $\mathrm{Ni}_{0.396} \mathrm{Zn}_{0.804} \mathrm{Fe}_{1.8} \mathrm{O}_{4}$ (B) ferrite.

only component with $A_{\text {rel }}=100 \%$ and $B_{\mathrm{HF}}=32.95 \mathrm{~T}$ without QS distribution area. Temperature dependences of magnetic susceptibility $\chi(T)$ of the sample A annealed within $850{ }^{\circ} \mathrm{C}$ to $1250^{\circ} \mathrm{C}$ in linear steps of $50^{\circ} \mathrm{C}$ are shown in Fig. 1. The dependences exhibit a Hopkinson peak $(\mathrm{HP})$ in the vicinity of the Curie temperature $\left(T_{\mathrm{C}}\right)$ and confirm phase purity of ferrite powders. The height of the HP decreases with increase of the temperature, which is connected with temperature dependence of total magnetic anisotropy $K_{t}$. Because the $K_{t}$ includes magnetocrystalline and size anisotropy, the HP is connected also with grain variation. It can be observed that at room temperature the susceptibility $\chi$ increases with annealing temperature. Stoichiometric powders of the composition $\mathrm{Ni}_{0.33} \mathrm{Zn}_{0.67} \mathrm{Fe}_{2} \mathrm{O}_{4}$ and $\mathrm{Ni}_{0.45} \mathrm{Zn}_{0.55} \mathrm{Fe}_{2} \mathrm{O}_{4}$ were thermally treated at the temperature $1200^{\circ} \mathrm{C} / 6 \mathrm{~h}$; the size of particle rose with temperature and it reached approximately $80 \mathrm{~nm}$. The $T_{\mathrm{C}}$ and magnetic susceptibility for sample A were $T_{\mathrm{C}}=110^{\circ} \mathrm{C}$ and $\chi_{(22)}=361.89$ a.u., respectively; see Fig. 1. For sample $\mathrm{C}$ it was $T_{\mathrm{C}}=224^{\circ} \mathrm{C}$ and $\chi_{(22)}=319.52$ a.u., see Fig. 2. The $T_{\mathrm{C}}$ of sample $\mathrm{C}$ is double that of A, see Figs. 1 and 2. A non-stoichiometric sample, where $x=0.2$, giving a summary formula $\mathrm{Ni}_{0.396} \mathrm{Zn}_{0.804} \mathrm{Fe}_{1.8} \mathrm{O}_{4}$, denoted as $\mathrm{B}$ is composed of a stoichiometric ferrite and additional $25 \%$ of nickel-zinc oxide blende. This two-phase system has values of $T_{\mathrm{C}}=218^{\circ} \mathrm{C}$ and $\chi_{(22)}=236.89$ a.u., respectively, see Fig. 2. Similar notion about non-stoichiometry was reported in [4] for $\mathrm{Zn}=0.24$, while in our compositions are $\mathrm{Zn}=0.55$ and 0.67. The measured magnetic parameters for sample B are initial permeability $\mu_{22}=91.25$; the temperature coefficient of initial permeability $\alpha_{\mu}=2.5 \times 10^{-4}{ }^{\circ} \mathrm{C}^{-1} ; H_{\mathrm{C}}=120 \mathrm{~A} / \mathrm{m}$ and $B_{\mathrm{r}} / B_{\mathrm{m}}=0.2132$ at $H_{\mathrm{m}}=10 \mathrm{~A} / \mathrm{m}$. For sample $\mathrm{C}$ value of $\alpha_{\mu}=1.04 \times 10^{-2}{ }^{\circ} \mathrm{C}^{-1}$ is two orders of magnitude higher than for $\mathrm{B}$, whereas the $T_{\mathrm{C}} \approx 220^{\circ} \mathrm{C}$ is for these samples nearly the same.

The frequency dependence of real and imaginary parts $\left(\mu^{\prime}\right.$ and $\mu^{\prime \prime}$ ) of complex initial permeability $\mu^{*}=\mu^{\prime}-\mathrm{j} \mu^{\prime \prime}$ for the sintered sample B is shown in Fig. 3. We observe the relaxation type of frequency dispersion of $\mu^{*}$. The $\mu^{\prime}$, which is about 53 at $1 \mathrm{MHz}$ (low frequency permeability), remained almost constant until the frequency was raised to a certain value, and then began to decrease at higher frequency $(\approx 9 \mathrm{MHz})$. The critical frequency $f_{\mathrm{c}}$ (resonance/relaxation) is about $56 \mathrm{MHz}\left(f_{\mathrm{c}}\right.$ is frequency at maximum of $\left.\mu^{\prime \prime}\right)$. The $\mu^{\prime \prime}$ gradually increased with the frequency, and reached a maximum of about 22 at about $56 \mathrm{MHz}$, where the real part $\mu^{\prime}$ rapidly decreased.

\section{Conclusion}

The stoichiometric A and $\mathrm{C}$ and iron-deficient B ferrites prepared by a wet method were studied and compared. The Curie temperature for sample $\mathrm{A}$ was $T_{\mathrm{C}}=$ $110^{\circ} \mathrm{C}$ and for the samples $\left(\mathrm{B}\right.$ and $\mathrm{C}$ ) was $T_{\mathrm{C}} \approx 220^{\circ} \mathrm{C}$, whereas the temperature coefficient of initial permeability for $\mathrm{A}$ and $\mathrm{C}$ was $\alpha_{\mu}=0.15-1.04 \times 10^{-2}{ }^{\circ} \mathrm{C}^{-1}$ and for sample B it was $\alpha_{\mu}=2.5 \times 10^{-4}{ }^{\circ} \mathrm{C}^{-1}$. The $f_{\mathrm{c}}$ of the sample $\mathrm{B}$ was about $50 \mathrm{MHz}$ and the low-frequency value of $\mu^{\prime}$ was about 53. This NiZn ferrite could be used as magnetic filler in magneto-polymers for microwave applications with appropriate temperature stability.

\section{Acknowledgments}

This work was supported by VG-1/0575/09, VG$-1 / 0529 / 10$ and VG-1/0606/09 grants of VEGA agency of the Slovak Republic.

\section{References}

[1] S. Singhal, S.K. Barthwal, K. Chandra, J. Magn. Magn. Mater. 296, 94 (2006).

[2] F. Li, X. Liu, Q. Yang, J. Liu, D.G. Evans, X. Duan, Mater. Res. Bull. 40, 1244 (2003).

[3] L. Zhiyuan, X. Maoren, Z. Qingqiu, J. Magn. Magn. Mater. 219, 9 (2000).

[4] M. Ušáková, J. Lukáč, R. Dosoudil, V. Jančárik, J. Mater. Sci., Mater. Electron. 18, 1183 (2007). 